\title{
Facial Motor Neuron Excitability in Hemifacial Spasm: A Facial MEP Study
}

\author{
Marshall F. Wilkinson, Anthony M. Kaufmann
}

\begin{abstract}
Introduction: Hemifacial spasm (HFS) may be due to peripheral axon ephapsis or central motor neuron hyperexcitability. Low facial motor evoked potential (MEP) thresholds or MEP responses to single pulse stimulation (normally multipulse stimulation is needed) may support the central hypothesis. Methods: We retrospectively compared response thresholds for facial MEPs in 65 patients undergoing surgical microvascular decompression (MVD) for HFS and 29 patients undergoing surgery for skull base tumors. Results: Single pulse stimulation elicited facial MEP in up to $87 \%$ of HFS patients whereas only $10 \%$ of tumor patients responded to single pulse stimulation. When comparing facial MEP thresholds using multi-pulse stimulus trains the voltage required in the HFS group were significantly lower then in skull base tumor patients $(\mathrm{P}<0.001)$. The MEP latencies and amplitudes at threshold stimulation were similar between the two groups. Conclusions: These results suggest the facial corticobulbar pathway demonstrates enhanced excitability in HFS.
\end{abstract}

RÉSUMÉ: Excitabilité du neurone moteur facial dans le spasme hémifacial : étude des PÉM. Contexte : Le spasme hémifacial (SHF) peut être dû à un éphapse au niveau d'axones périphériques ou à une hyperexcitabilité du neurone moteur central. Le fondement de l'hypothèse centrale repose sur des seuils bas de potentiels évoqués moteurs (PÉM) faciaux ou des réponses PÉM à une impulsion unique (normalement, plusieurs impulsions sont nécessaires). Méthode : Nous avons comparé rétrospectivement les seuils de réponse des PÉM faciaux chez 65 patients soumis à une chirurgie de décompression microvasculaire pour un SHF et chez 29 patients soumis à une chirurgie pour une tumeur située à la base du crâne. Résultats : L'impulsion unique a provoqué des PÉM faciaux chez $87 \%$ des patients atteints de spasme hémifacial alors que seulement $10 \%$ des patients présentant une tumeur y ont répondu. La comparaison des seuils de PÉM faciaux au moyen d'un train d'impulsions multiples a révélé que le voltage nécessaire dans le groupe SHF était significativement inférieur à celui qui était nécessaire dans le groupe de patients présentant une tumeur de la base du crâne ( $\mathrm{p}$ $<0,001)$. La latence et l'amplitude des PÉM au seuil de stimulation étaient similaires dans les deux groupes. Conclusions : Ces résultats indiquent qu'il existerait une excitabilité accrue de la voie corticobulbaire faciale chez les patients atteints de SHF.

Can J Neurol Sci. 2014; 41: 239-245

Hemifacial spasm (HFS) is an involuntary and irregular spasm of the facial muscles innervated by the VII cranial nerve that typically progresses in severity and extent over time. The etiology of HFS has been attributed to vascular compression of the facial nerve at the root exit zone $(\text { REZ })^{1}$. This led to the development of surgical microvascular decompression (MVD) of this cranial nerve by Jannetta and colleagues ${ }^{2}$ for the treatment of HFS. This group also advocated the use of intraoperative neurophysiological monitoring to minimize iatrogenic injuries as well as an aid to the surgical procedure. Specifically, Moller and Janetta described the lateral spread (LS) response, an electromyographic hallmark specific to $\mathrm{HFS}^{3-5}$. This LS response is produced by electrical stimulation of one branch of the facial nerve and observing the electromyographic response in the facial musculature innervated by a different branch of the nerve.

The neurophysiological mechanism of the LS response has been hotly debated between those that favor a peripheral mechanism $^{6,7}$ versus a centrally mediated hypothesis ${ }^{3-5}$. We sought to explore this debate by observing facial motor evoked potentials and LS responses during MVD surgeries for $\mathrm{HFS}^{8}$. We found that facial motor evoked potential (MEP) amplitude and duration became markedly reduced, coincident with the LS response, following the surgical microvascular decompression and concluded that the data was consistent with a LS mechanism that was likely centrally mediated. Similar results have been replicated using the multipulse stimulation method ${ }^{9-12}$ however, others have disagreed with our methods and conclusions ${ }^{9,13}$.

Multiple pulse stimulation is a requirement for generating facial MEPs ${ }^{14-16}$. We, however, have found single pulse transcranial electrical stimulation evokes putative corticobulbar evoked potentials in HFS patients ${ }^{8}$. This finding suggests that facial MEP responses in HFS may have a lower threshold for activation, in keeping with a central hyperactivity mechanism in this disease. To further evaluate the neurophysiological responses in HFS, we now report our observations, of the threshold stimulation voltage obtained for facial MEPs in patients undergoing MVD surgery for HFS and skull base tumor surgery.

\footnotetext{
From the Section of Neurosurgery, Health Sciences Centre and University of Manitoba, Winnipeg, Manitoba, Canada.

Received February 15, 2013. Final Revisions Submitted September 23, 2013. Correspondence to: Marshall Wilkinson, GB137 - Section of Neurosurgery, Health Sciences Centre and University of Manitoba, 820 Sherbrook Street, Winnipeg, Manitoba, R3A 1R9, Canada. Email: mwilkinson@hsc.mb.ca.
} 


\section{METHODS}

Intraoperative neurophysiological recording data were retrospectively reviewed from a consecutive series of 118 HFS and 54 skull base tumor patients operated on between 2006 and 2011. The eligibly criteria for this analysis required successful facial MEP recordings using single and/or multiple pulse stimulation and a pulse width of $50 \mu \mathrm{s}$. The MEP stimulation montage was either $\mathrm{C} 3-\mathrm{C} 4$ or $\mathrm{C} 4-\mathrm{C} 3$ configuration (referred as $\mathrm{C} 3 / \mathrm{C} 4$ ) or $\mathrm{C} 3 / \mathrm{C} 4-\mathrm{Cz}$. Sufficient recordings of facial MEP were obtained and available for analysis from 65 patients with HFS and 29 with skull base tumors. Facial MEPs were considered centrally derived when onset latencies were $>10 \mathrm{~ms}^{14,16}$ while extracranial activation of the facial nerve by current spread was attributed to short latency activation (onset latency $<10 \mathrm{~ms}$ ). Stimulus pulse widths other then $50 \mu$ s were excluded because the stimulus voltage was used as the measure of the activation threshold and a higher pulse width may require less voltage for a response.

Patients were excluded from the analysis because of technical failure to obtain a facial MEP $(\mathrm{n}=34)$, which included no responses or short latency extracranially activated contamination, MEP test not performed $(n=4)$, stimulation pulse widths $>50 \mu$ s $(\mathrm{n}=16)$, or an insufficient number of stimulation trials to accurately determine threshold voltage $(\mathrm{n}=$ 24). This data is summarized in Table I. The proportions of patients within each exclusion category did not significantly differ between the patient groups. However, short latency responses were higher in the skull base tumor group $(\mathrm{p}=0.063$, $\chi^{2}$ ). This may be due to the higher stimulus voltage needed in this group which resulted in short latency responses more often, particularly using the $\mathrm{C} 3 / \mathrm{C} 4$ montage.
All patients were referred to the Centre for Cranial Disorders at our hospital and operated on by a single neurosurgeon (AMK). Neurophysiologic monitoring was performed by a monitoring team of three people including one of the authors (MFW). Magnetic resonance imaging (MRI) was performed in all patients and was the primary diagnostic instrument in tumor patients. Included in the analysis were patients with diagnosis of meningioma $(n=13)$, vestibular schwannoma $(n=8)$, ependymoma $(n=2)$, epidermoid $(n=2)$ and one each of hemangioblastoma, arachnoid cyst, medulloblastoma, chondrosarcoma and clivus chordoma. In the HFS group diagnosis was made primarily based on clinical criteria. No patient had preoperative facial nerve palsy (House-Brachmann $\leq$ II). Approval for this study was given by our institutional ethics review board.

Our monitoring protocol included electromyelogram (EMG) studies with paired subdermal electrodes (Medtronic) inserted into the ipsilateral orbicularis oculi, orbicularis oris and mentalis muscles for observing free running EMG responses. Transcranial MEPs were recorded from these same facial muscles. Data were amplified, displayed and filtered (100 $3000 \mathrm{~Hz}$ ) using a commercial workstation (Cadwell Cascade). Anesthesia was maintained with infusions of propofol $(20-100$ $\mu \mathrm{g} / \mathrm{kg} / \mathrm{min})$ and remifentanyl $(0.08 \quad-0.125 \mu \mathrm{g} / \mathrm{kg} / \mathrm{hr})$ supplemented with desflurane or occasionally sevoflurane at $\leq$ 0.5 MAC. This was used for all MVD and tumor procedures. Mean arterial pressures were maintained within the normal range for each patient using infusions of phenylephrine as necessary and ventilator $\mathrm{CO}_{2}$ levels were maintained at 33 - 35. Neuromuscular blockers were withheld following intubation and evaluation of the recovery of neuromuscular blockade was assessed by observing the mentalis muscle $M$ wave when stimulating the mandibular branch using a train of 4 .

Table 1: Inclusion/exclusion data for each patient group. Threshold data from the $\mathrm{C3} / \mathrm{C} 4$ and $\mathrm{C} 3 / \mathrm{C} 4-\mathrm{Cz}$ stimulus montages using $50 \mu$ s pulse widths were included as indicated

\begin{tabular}{|c|c|c|c|c|c|c|}
\hline \multirow[b]{2}{*}{ All patients } & \multicolumn{2}{|l|}{ HFS } & \multicolumn{3}{|l|}{ Skull base } & \multirow{2}{*}{$\begin{array}{r}\text { total } \\
172\end{array}$} \\
\hline & \multicolumn{2}{|r|}{118} & & & 54 & \\
\hline No MEP test & & 4 & & & 0 & 4 \\
\hline Other MEP methods & Pulse width & & Pulse width & 8 & 8 & 16 \\
\hline \multirow[t]{2}{*}{ Technical failure } & Short latency & \multirow{2}{*}{19} & Short latency & 12 & \multirow{2}{*}{15} & \multirow{2}{*}{34} \\
\hline & No response & & No response & 3 & & \\
\hline Insufficient data & & 22 & & & 2 & 24 \\
\hline \multirow[t]{3}{*}{$\begin{array}{l}50 \mu \mathrm{s} \text { PW } \\
\mathrm{C} 3 / \mathrm{C} 4\end{array}$} & $\begin{array}{l}1 \text { pulse } \& \text { multi } \\
\text { pulse test }\end{array}$ & \multirow{3}{*}{40} & $\begin{array}{l}1 \text { pulse } \& \text { mult } \\
\text { pulse test }\end{array}$ & 10 & \multirow{3}{*}{20} & \multirow{3}{*}{60} \\
\hline & 1 pulse only & & 1 pulse only & 0 & & \\
\hline & Multipulse only & & Multipulse only & 10 & & \\
\hline \multirow[t]{3}{*}{$\begin{array}{l}50 \mu \mathrm{s} P W \\
\mathrm{C} 3 / \mathrm{C} 4-\mathrm{Cz}\end{array}$} & $\begin{array}{l}1 \text { pulse } \& \text { multi } \\
\text { pulse test }\end{array}$ & \multirow[t]{3}{*}{25} & $\begin{array}{l}1 \text { pulse } \& \text { mult } \\
\text { pulse test }\end{array}$ & 0 & \multirow[t]{3}{*}{9} & \multirow[t]{3}{*}{34} \\
\hline & 1 pulse only & & 1 pulse only & 0 & & \\
\hline & Multipulse only 8 & & Multipulse only & 9 & & \\
\hline
\end{tabular}

$\mathrm{PW}=$ pulse width, HFS = hemifacial spasm, MEP = motor evoked potential 
We evaluated the facial MEP data from both patient groups where the stimulation montage was $\mathrm{C} 3 / \mathrm{C} 4$ or $\mathrm{C} 3 / \mathrm{C} 4-\mathrm{Cz}$. Lead locations were determined according to the international 10-20 system and the anode was contralateral to the symptomatic side. Occasionally the anode was repositioned $1 \mathrm{~cm}$ posteriorly to reduce jaw movement or eliminate short latency facial nerve activation. Motor evoked potential responses for this analysis were collected prior to dural opening. In HFS and skull base tumor patients we compared the MEP stimulation voltage threshold in response to single pulse stimulus and multiple $(\geq 3)$ pulse stimulation trains (interpulse interval $1 \mathrm{~ms}$ ) as well as MEP onset latency times and amplitude at stimulation threshold. We defined threshold as the minimum voltage required to elicit a facial MEP of $\geq 30 \mu \mathrm{V}$ in at least $50 \%$ of a minimum of eight consecutive stimulation trials (modified from ${ }^{17}$ ). Statistical analysis for multiple comparisons was performed using the Kruskal-Wallis one way analysis of variance on ranks and pairwise comparisons were performed using the Mann-Whitney $\mathrm{U}$ test. Proportions were evaluated using a $\chi^{2}$ test. Significance was considered with $\mathrm{p}<0.05$.

\section{RESULTS}

Single Pulse Stimulation: Among the HFS patients, 32 of 40 received single pulse stimulation using a $\mathrm{C} 3 / \mathrm{C} 4$ stimulus montage and 17 of 25 via the C3/C4-Cz montage. Facial MEPs meeting the centrally derived criteria ${ }^{14,16}$ were elicited in $87 \%$ (28/32) of HFS patients (C3/C4 montage) with a mean threshold voltage of $111.6 \pm 46.5 \mathrm{~V}$ (mean \pm S.D.). For 20 skull base tumor patients tested with the C3/4 montage, 10 were tested with both single pulse stimulation and multipulse stimulation for facial MEP. Single pulse stimulation was given using the same intensity as that utilized for successful multipulse facial MEPs. In contrast to HFS patients, only 1/10 (10\%) of these skull base tumor patients had facial MEP responses with single pulse stimulation. Using the $\mathrm{C} 3 / \mathrm{C} 4-\mathrm{Cz}$ montage, 17 of 25 HFS patients were tested with single pulse stimulation. From these 17 people, 13 responded with centrally derived facial MEP response $(76.5 \%)$ at a MEP threshold of $158.1 \pm 63.6 \mathrm{~V}$ (mean \pm S.D.). Examples of single pulse activation of facial MEPs in HFS patients, using both stimulus montages, are shown in Figure 1. Of the ten skull base tumor patients using $\mathrm{C} 3 / \mathrm{C} 4-\mathrm{Cz}$ none were tested for single pulse facial MEP activation and in one other patient only short latency responses could be generated. (Figure 2B).

Threshold changes for single pulse stimulation were assessed in some HFS patients following the MVD but before craniotomy closure. Among these 17 patients, 13 (76\%) no longer responded with facial MEPs to single pulse transcranial electrical stimulation. The four patients that did respond to single pulse stimulation at the pre-MVD threshold had facial MEP amplitudes that were 52\% less following decompression (see Figure 1). There were no instances of neurotonic EMG potentials (indicative of axonal injury) during the MVD procedures and no HFS patient had facial weakness postoperatively. This suggests that the MEP threshold changes were not due to surgical injury to the facial nerve. We are currently investigating this further using a prospective protocol which includes quantifying MEP thresholds before and after decompression.
Multiple Pulse Stimulation: Comparison of multipulse stimulation thresholds between HFS and skull base tumor patients showed a significant difference between the groups (Figure 2A, 2B). Using the $\mathrm{C} 3 / \mathrm{C} 4$ stimulus montage, the mean threshold voltage for evoking a facial MEP response in HFS patients $(\mathrm{n}=34)$ was $111.3 \pm 49.0 \mathrm{~V}$ (mean \pm S.D.), whereas in $(\mathrm{n}=20)$ skull base tumor patients the threshold voltage was $182.8 .7 \pm 70.2 \mathrm{~V}(\mathrm{p}<0.001$, Kruskal-Wallis one way ANOVA, single pulse HFS vs skull base; multipulse HFS vs. skull base).

We also noted that when both single and multiple stimulation pulses were applied in the same HFS patients (C3/C4 montage) the mean threshold voltage for facial MEP responses was not different, and in many cases the thresholds were identical (Figure 2A, 2B). Utilizing the $\mathrm{C} 3 / \mathrm{C} 4-\mathrm{Cz}$ montage resulted in a multipulse MEP threshold of $166.0 \pm 48.3 \mathrm{~V}$ in HFS $(n=19$, with six exclusions; three no response, one insufficient trials, two short latency responses) and $227.0 \pm 65.2 \mathrm{~V}$ in skull base tumor patients $(n=9$; one exclusion short latency response) $(\mathrm{p}<$ 0.05 , Kruskal-Wallis one way ANOVA, single pulse HFS vs skull base; multipulse HFS vs. skull base). (Figure 2)

Response latency and amplitude at threshold: Although we cannot completely rule out that the skull base tumor patients were hypo-responsive to facial MEP generation, the measurable electrophysiological parameters between the patient groups were similar and no patients were tested with demonstrable clinical facial weakness. Facial MEP response onset latencies were similar between the three recorded facial muscles in both HFS patients and skull base surgery patients (Table II). For example the mean latency for the single pulse MEP response from the 0 . oris, in HFS patients, was $14.0 \pm 2.1 \mathrm{~ms}$ and $14.4 \pm 2.7 \mathrm{~ms}$ when responses were evoked with multipulse stimulation. Similar latencies were observed from skull base surgery patients where the multi-pulse stimulation elicited mean o. oris latencies of 14.3 $\pm 2.1 \mathrm{~ms}$ ( $\mathrm{p}=0.61$, Mann-Whitney, compared to multipulse HFS o. oris). A box plot showing the MEP onset latency distributions from the o.oris in our three groups is shown in Figure 3. Statistical differences between the other facial muscles were also

Table 2: Mean latencies $( \pm$ SD) from facial muscle MEP (C3/C4 montage) in HFS and skull base skull base tumor patients

\begin{tabular}{l|l|l|l}
\hline & o. oculi & o. oris & mentalis \\
\hline Single pulse HFS & $13.0 \pm 1.9(6)$ & $14.0 \pm 2.1(14)$ & $13.5 \pm 1.5(17)$ \\
\hline Multiple pulse HFS & $12.8 \pm 2.2(12)$ & $14.4 \pm 2.7(26)$ & $13.1 \pm 2.0(21)$ \\
\hline Multiple pulse skull base & $15.5 \pm 3.6(2)$ & $14.3 \pm 2.1(12)$ & $12.5 \pm 2.0(6)$ \\
\hline
\end{tabular}

Note that all 3 muscles did not always respond simultaneously to transcranial stimulation. Thus the numbers in parentheses refer to the number of responding muscles used in the latency determination. Number of patients available for analysis within each treatment group are shown in parentheses. HFS = hemifacial spasm, MEP = motor evoked potential, O. Oculi $=$ orbicularis oculi, O. Oris $=$ orbicularis oris. 


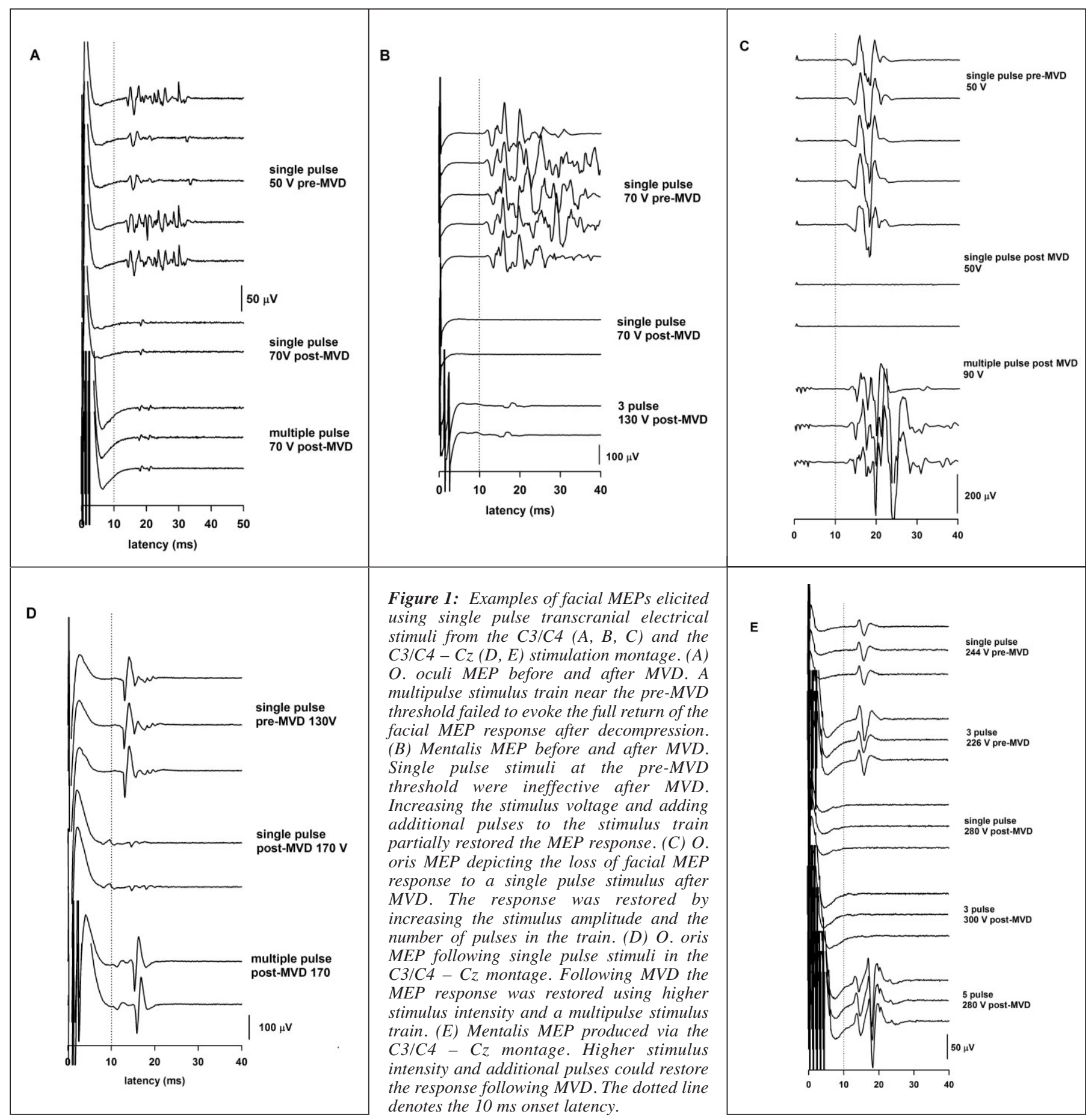

not evident. Threshold facial MEP amplitudes (peak-to-peak) were also compared as this can indicate the number of axons contributing to the $\mathrm{MEP}^{18}$. The mean amplitude for the threshold response for the o. oris MEP in the tumor group was 101.8 \pm 49.5 $\mu \mathrm{V}$ and the HFS group was $90.6 \pm 58.9 \mu \mathrm{V}(\mathrm{p}=0.2$, Mann Whitney). Thus the only demonstrable difference between the two patient groups was the stimulus voltage needed for the threshold facial MEP response.

\section{DISCUSSION}

The major outcomes of this study are: 1) in the majority of HFS patients, prior to alleviation of culprit neurovascular contact, a single pulse stimulus paradigm was sufficient to elicit facial MEPs, and this response disappeared after microvascular decompression in $76 \%$ of those tested; 2) multi-pulse stimulation threshold for facial MEP response in HFS patients were significantly lower compared to skull base tumor patients; and 3) 
the facial MEP response latencies and amplitudes were similar between the two patient groups suggesting that compromised facial nerve function in the skull base tumor patients, as assessed clinically and electro-physiologically, seems unlikely.

The present data confirm our previous study demonstrating that in patients with HFS, facial MEPs can be produced using single pulse transcranial stimulation prior to $\mathrm{MVD}^{8}$. While our original paper reported facial MEP latencies that often contained elements of extracranial facial nerve activation (7 - $8 \mathrm{~ms}$ range) we subsequently demonstrated that this did not detract from the change in the amplitude and duration of the later, centrally mediated, components following $\mathrm{MVD}^{19}$. Using more stringent criteria we repeat those results here and extend them by quantifying facial motor neuron excitability differences in two patient groups. Furthermore the MEP response to single pulse

A

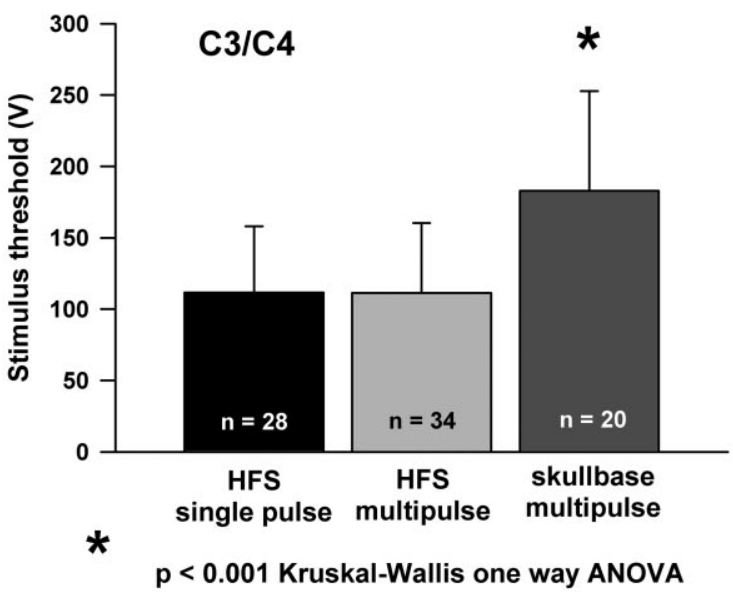

B

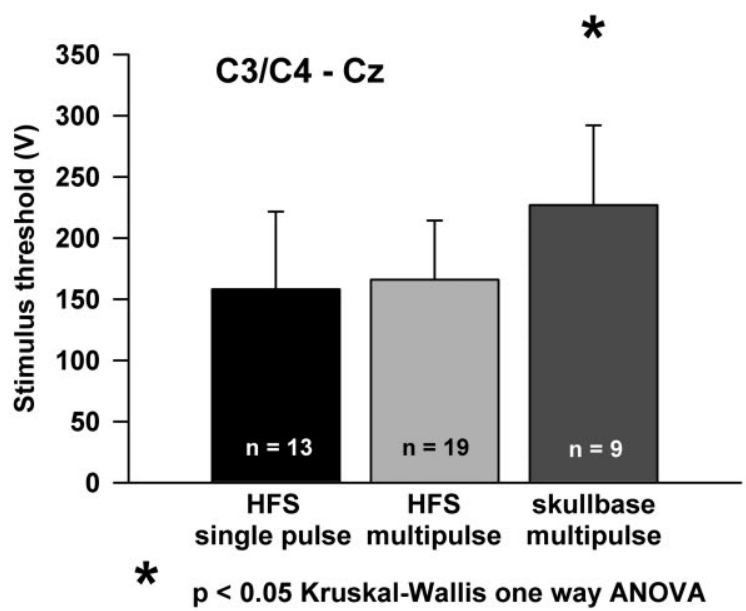

Figure 2: Mean ( $\pm S D$ ) facial MEP stimulation threshold values from HFS and skull base skull base tumor patients stimulated with single pulse or multipulse stimulation trains using the $C 3 / C 4(A)$ or $C 3 / C 4-C z$ montage $(B)$. Threshold was determined from one of the three facial muscles in the recording montage. A clear and statistically significant difference was evident. transcranial electrical stimulation in HFS patients during MVD operations has now been acknowledged by others ${ }^{20}$.

The present study shows that incorporating additional pulses into the stimulation train does not change the facial MEP threshold response in the HFS group. Since a multi-pulse stimulation train delivers a much larger electrical charge ${ }^{19}$, one might predict that this paradigm would lead to lower response thresholds but this was not observed. In contrast, skull base tumor patients require a multiple pulse stimulation train to elicit facial MEP responses and the response thresholds in this group were much higher. The requirement for multipulse-induced facial MEP in non-HFS subjects confirms that previously described for corticobulbar MEP of the facial nerve as well as the vagus nerve 14-16,21. $^{2}$

It has been argued that a facial muscle MEP response to single pulse transcranial stimulation must be artifactual because temporal summation is required to evoke "true" corticobulbar responses ${ }^{13,14,16,21}$. In the present analysis we rigorously excluded any results where there was even small degree of muscle depolarization occurring in advance of $10 \mathrm{~ms}$. Responses with latencies $<10 \mathrm{~ms}$ would indicate extracranial activation of the facial nerve ${ }^{14,16,21}$. However, when we applied a single pulse stimulation paradigm in HFS patients we observed facial MEP responses $76 \%$ of the time using the $\mathrm{C} 3 / \mathrm{C} 4-\mathrm{Cz}$ stimulation montage and $86 \%$ of the time using the $\mathrm{C} 3 / \mathrm{C} 4$ montage. All these responses were evoked with latencies well in excess of 10 ms (Figure 1 and 3). This contrasts the observation in skull base tumor patients where a single pulse stimulation paradigm was generally ineffective at evoking MEP responses.

The significance of these observations likely relates to the pathophysiology of HFS. There has been debate between proponents of the non-central ephaptic transmission theory ${ }^{6,7}$ and a central hyperactive facial nucleus theor ${ }^{3-5}$. We, and others,

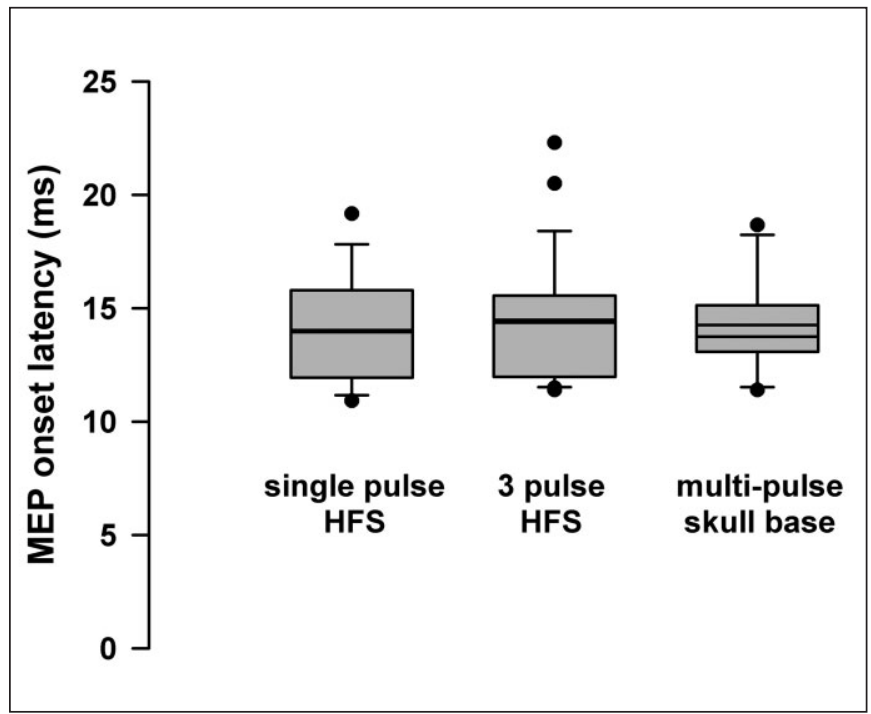

Figure 3: A box plot representation of onset latency data from the o. oris muscle in the three patient groups. Error bars represent the 5th and 95th percentile about the mean and median (centre lines). Outliers are plotted in each condition. 
have observed that the lateral spread responses decrease or disappear more or less simultaneously with changes in the facial MEP responses ${ }^{8,10-12,20}$. This temporal link between the lateral spread response and the facial MEP is compelling and suggests altered facial motor nucleus excitability in HFS rather than a mechanism acting distally or putative changes occurring elsewhere along the corticobulbar pathway.

Our present observations of reduced stimulation threshold and successful generation of facial MEP using single pulse stimulation in HFS is supportive of altered facial motor neuron excitability and the central hyperactivity theory. In the majority of HFS patients prior to decompression, facial motor neurons are in a sufficient excitation state such that temporal summation for facial MEPs is not necessary for depolarization. This is consistent with F-wave studies demonstrating hyperactive or decreased response thresholds for F-waves in HFS patients prior to MVD surgery ${ }^{22-24}$. Our data are also consistent with Moller's original observations demonstrating successful blink reflex responses on the spasm side of HFS patients, using single pulse stimulation of the supraorbital nerve ${ }^{25-27}$. In non-HFS patients the blink reflex is notoriously difficult to obtain under anesthesia but can be evoked using multipulse stimulation trains ${ }^{28}$. Finally, reduced facial MEP response thresholds using transcranial magnetic stimulation have also been demonstrated on the spasm side of patients with HFS $^{29}$. Collectively these results are consistent with a central hyperactivity mechanism contributing to the pathophysiology of HFS. An additional and intriguing contribution to facial nerve excitability in HFS is the role of the trigeminal nerve ${ }^{30}$. How trigeminal influences might affect facial MEP responses remains to be elucidated.

In this retrospective analysis the MEP response threshold differences between HFS and skull base tumor patients were found to be significantly different. Moreover we have demonstrated that the MEP response to a single transcranial stimulus pulse is a trademark of HFS and not other patient groups. A drawback of this work is the comparatively small number of patients who were available for study. Many patients were excluded from the analysis because of the use of alternate stimulus parameters, technical failures or too few stimulation trials to accurately determine threshold. The largest number of patient data for comparison was from facial MEPs elicited using the $\mathrm{C} 3 / \mathrm{C} 4$ stimulus configuration. This unfortunately resulted in a failure rate (i.e. short latency response) of $13 \%$. The facial MEP data using the $\mathrm{C} 3 / \mathrm{C} 4-\mathrm{Cz}$ stimulus montage resulted in similar threshold trends, although with a lower failure rate of $8 \%$. However there were a smaller number of patients to analyze, particularly skull base tumor patients. A major reason for this is that facial MEP using C3/C4 stimulus montage typically requires lower stimulus intensity, albeit with a greater failure rate, so that patient movement is less frequent and the risk of volume conducted muscle potentials activated by other cranial nerves is minimized. Moreover, in several skull base tumor patients facial MEP responses could only be elicited using the $\mathrm{C} 3 / \mathrm{C} 4$ stimulus method. As a rule we avoid using stimulus amplitudes of $>300$ $\mathrm{V}$ to minimize the risk for non-specific facial muscle recordings (i.e., masseter or hypoglossal muscle depolarization being detected by facial muscle leads). We now test both montages and use the one that results in the least patient movement coupled with specific facial MEP recordings. It is important to be aware that stimuli strong enough to activate other nearby muscles (masseter, hypoglossal) could lead to facial nerve false negative monitoring via volume conduction. Therefore stimulus intensity should be kept to a minimum, conducive with successful neuromonitoring.

In conclusion we demonstrate for the first time that facial MEP thresholds are significantly lower in HFS compared to skull base tumor patients undergoing similar facial nerve monitoring. We also demonstrate that in HFS facial MEP responses elicited with single pulse stimulation are indeed corticobulbar generated and reflective of altered facial motor nucleus excitability not evident in other patient groups.

\section{REFERENCES}

1. Jannetta PJ. Microsurgical exploration and decompression of the facial nerve in hemifacial spasm. Curr Top Surg Res. 1970;2: 217-20.

2. Jannetta PJ, Abbasy M, Maroon JC, et al. Aetiology and definitive microsurgical treatment of hemifacial spasm. J Neurosurg. 1977; 47:321-8.

3. Moller AR, Jannetta PJ. Microvascular decompression hemifacial spasm: intraoperative electrophysiological observations. Neurosurg. 1985;16:612-18.

4. Moller AR, Jannetta PJ. Physiological abnormalities in hemifacial spasm studies during microvascular decompression operations. Exp Neurol. 1986;93:584-600.

5. Moller AR, Jannetta PJ. Monitoring facial EMG responses during microvascular decompression operations for hemifacial spasm. J Neurosurg. 1987;66:681-5.

6. Neilsen VK. Electrophysiology of the facial nerve in hemifacial spasm: ectopic/emphatic excitation. Muscle Nerve. 1985;8: 545-55.

7. Neilsen VK. Pathophysiology of hemifacial spasm: I. Ephaptic transmission and ectopic excitation. Neurology. 1984;34:418-26.

8. Wilkinson M, Kaufmann AM. Monitoring of facial muscle motor evoked potentials during microvascular decompression for hemifacial spasm: evidence of changes in motor neuron excitability. J Neurosurg. 2005;103:64-9.

9. Ulkatan S, Deletis V, Fernandez-Conejero I. Central or peripheral activation of the facial nerve? J Neurosurg. 2007;106(3):519-20.

10. Fukuda M, Oishi M, Hiraishi, T, Fujii, Y. Facial nerve motorevoked potential monitoring during microvascular decompression for hemifacial spasm. J Neurol Neurosurg Psychiatry. 2010;81:519-23.

11. Fukuda M, Oishi M, Takao T, Hiraishi T, Sato Y, Fujii Y. Monitoring of abnormal muscle response and facial motor evoked potential during microvascular decompression for hemifacial spasm. Surg Neurol Int. 2012;3:118.

12. Fukuda M, Oishi M, Hiraishi T, Fujii Y. Facial nerve motor-evoked potential monitoring during microvascular decompression for hemifacial spasm. J Neurol. Neurosurg Psychiatry. 2013;81: 519-23.

13. MacDonald DB. Intraoperative motor evoked potentials? J Neurosurg. 2007;106(3):517-18.

14. Dong CJ, MacDonald D, Akagami, R, et al. Intraoperative facial motor evoked potential monitoring with transcranial electrical stimulation during skull base surgery. Clin Neurophysiol. 2005; 116:588-96.

15. Lui BY, Tian YJ, Lui SL, Qiao H, Zhang JT, Jia GJ. Intraoperative facial motor evoked potentials monitoring with transcranial electrical stimulation for preservation of facial nerve function in patients with large acoustic neuroma. Chin Med J. 2007;120(4): 323-5.

16. Matthies C, Raslan F, Schweitzer T, Hagen R, Roosen K, Reiners K. Facial motor evoked potentials in cerebellopontine angle surgery: technique, pitfalls and predictive value. Clin Neurol Neurosurg. 2011;113(10):872-9. 
17. Brocke $\mathrm{J}$, Irlbacher $\mathrm{K}$, Hauptmann $\mathrm{B}$, Voss $\mathrm{M}$, Brandt SA. Transcranial magnetic and electrical stimulation compared: does TES activate intracortical neuronal circuits? Clin Neurophysiol. 2005; 116:2748-56.

18. Moller AR. Intraoperative Neurophysiological Monitoring. 3rd ed. New York; Springer; 2011.

19. Wilkinson MF, Kaufmann AM. Intraoperative motor evoked potentials? J Neurosurg. 2007;106:517-20.

20. Fernandez-Conejero I, Ulkatan S, Sen C, Deletis V. Intra-operative neurophysiology during microvascular decompression for hemifacial spasm. Clin Neurophysiol. 2012;123:78-83.

21. Deletis V, Fernandez-Conejero I, Ulkatan S, Constantino P. Methodology for intraoperatively eliciting motor evoked potentials in the vocal muscles by electrical stimulation of the corticobulbar tract. Clin Neurophysiol. 2009;120:336-41.

22. Ishikawa $\mathbf{M}$, Ohira $\mathrm{T}$, Namiki $\mathrm{J}$, et al. Electrophysiological investigation of hemifacial spasm after microvascular decompression: $\mathrm{F}$ waves of the facial muscles, blink reflexes, and abnormal muscle responses. J Neurosurg. 1997;86:654-61.

23. Ishikawa $\mathbf{M}$, Nimiki $J$, Takase $\mathbf{M}$, et al. Effect of repetitive stimulation on lateral spread and F-waves in hemifacial spasm. J Neurol Sci. 1996;142:99-106.
24. Ishikawa M, Ohira T, Namiki J, et al: Abnormal muscle response (lateral spread) and F-Wave in patients with hemifacial spasm. J Neurol Sci. 1996;137:109-16.

25. Moller AR, Janetta, PJ. Blink reflex in patients with hemifacial spasm: observations during microvascular decompression operations. J Neurol Sci. 1986;72:171-82.

26. Moller AR, Janetta, PJ. Physiological abnormalities in hemifacial spasm studied during microvascular decompression operations. Exp Neurol. 1986;93:584-600.

27. Moller AR. Interaction between blink reflex and the abnormal muscle response in patients with hemifacial spasm: results of intraoperative recording. J Neurol Sci. 1991;101:114-22.

28. Deletis V, Urriza J, Ulkatan S, Fernandez-Cornejo I, Lesser J, Mista D. The feasibility of recording blink reflexes under general anesthesia. Musc Nerve. 2009;39:642-6.

29. Kojima A, Ohira T, Takase M, et al. Long-latency response to transcranial magnetic stimulation in patients with hemifacial spasm. Electroencephalogr Clin Neurophysiol. 1998;109:285-9.

30. Ishikawa M, Takashima K, Kamochi H, Kusaka G, Shinoda S, Watanabe E. Treatment with botulinum toxin improve the hyperexcitability of the facial motorneuron in patients with hemifacial spasm. Neurol Res. 2010;32:656-60. 